\title{
В перспективе мы видим себя в роли корпоративного центра производства печатных плат
}

\author{
Визит на Азовский оптико-механический завод
}

\section{В. Мейлицев}

\begin{abstract}
Акционерное общество "Азовский оптико-механический завод" (АОМЗ) начало выпускать продукцию, содержащую электронные узлы, еще в 1960-х годах. С тех пор и по сегодняшний день предприятие само изготавливает платы для своих устройств. За время существования завода его производство печатных плат пережило три полномасштабных технологических перевооружения, последнее из которых завершилось в текущем году. Приехав на АОМ3, мы попросили показать, чем сегодня располагает цех изготовления печатных плат и каков уровень выпускаемой им продукции. Разговор начался в кабинете первого заместителя генерального директора Акционерного общества "Азовский оптико-механический завод" Василия Валерьевича Аксёнова.
\end{abstract}

Василий Валерьевич, расскажите немного об истории завода.

Акционерное общество «Азовский оптико-механический завод", носившее тогда другое название, начинало с изготовления агрегатов сельскохозяйственных машин и оборудования для производства сельхозтехники. В течение нескольких последующих лет номенклатура выпускаемой продукции расширялась и изменялась, но кардинальное перепрофилирование завода связано с именем его многолетнего (с 1956 по 1987 годы) директора Николая Георгиевича Васильева. За время его руководства на АОМЗ были освоены разработка и производство широкого спектра оптико-механических и оптико-электронных приборов от бытовой и медицинской техники до агрегатов космических аппаратов. Вместе с первым оптико-электронным изделием у нас начало развиваться и изготовление электронных узлов и, соответственно, плат для них - сначала несущих, а потом и печатных.

И какими же они были, эти первые печатные платы?

В 1972 году на базе штамповочного цеха был организован участок производства печатных плат (ПП), с 1974 года преобразованный в цех. Цех изготавливал одно- и двухсторонние платы негативным методом, переходные отверстия прошивались медной проволокой, металлизировались и гальванически затягивались - гальваническая технология у нас к тому времени уже давно была освоена.

Следующий этап развития производства ПП пришелся на 1980-е годы, когда в Москве на выставке было приобретено новое оборудование, в частности, химико-гальваническая линия швейцарской фирмы STS. Этот комплект машин позволил выпускать платы, соответствующие 3 и 4 классам точности. Многослойные ПП (МПП) мы делали тогда по методу открытых контактных площадок: в вышележащих слоях прессом вырубаются окошки до контактных площадок на внутреннихслоях, и после прессования пакета на эти площадки монтируются выводы компонентов. Таким образом мы изготавливали 12-, 16- и даже 18-слойные ПП, надолго обеспечив потребности предприятия в этой части комплектации наших изделий.

Почему потребовался следующий этап развития производства печатных плат?

Думаю, это очевидно. Требования по расширению функционала и по минимизации массо-габаритныххарактеристик приборов постоянно растут, и возможности микроэлектроники позволяют следовать этим требованиям: микросхемы становятся все более производительными и многофункциональными, растут частоты каналов передачи данных внутри электронного узла, продолжается процесс микроминиатюризации электронных компонентов. Для разработчиков ПП это означает рост плотности монтажа и предъявление требований в части СВч-характеристик, а для технологов - необходимость уменьшения размеров основных элементов топологического рисунка ПП, допусков на их воспроизведение и освоения специальных материалов. Параллельно с этим возрастает роль качества, стоимости и надежности как самих изделий, так и технологических процессов, в ходе которых они изготавливаются. 
Некоторое время нам приходилось заказывать особо сложные МПП на другом предприятии, но было ясно, что нужно полностью переоснастить собственное производство. И это сделано: при помощи средств Федеральных целевых программ мы в три этапа создали новый технологический комплекс. На нем мы можем производить многослойные - до 24 слоев - ПП, в том числе высокочастотные, максимальным размером 610 × 457 мм, толщиной до 3,2 мм. По основным параметрам это платы 5 класса точности, а по некоторым элементам - до 7-го: минимальная ширина проводников / зазоров 0,05 / 0,07 мм с точностью 5 мкм, максимальное отношение диаметра металлизированного отверстия к его глубине 1:20. Кроме того, на этом оборудовании могут изготавливаться гибко-жесткие ПП, платы на металлическом основании, гибкие печатные схемы.

\section{Когда запущен новый комплекс оборудования?}

Оборудование было запущено в эксплуатацию в начале текущего года. Последняя закупка МПП у сторонней организации прошла в апреле-мае. В этом интервале времени мы провели цикл испытаний, подтвердивший способность комплекса производить платы с требуемыми параметрами точности, подписали все официальные акты. Одновременно переработали под новую технологию конструкторскую документацию (КД), подготовили маршрутнооперационные описания технологических процессов.

Должен отметить, что вся эта работа была сделана совместно с компанией "Остек-СТ». Выбор этой компании для долгосрочного партнерства обусловлен тем, что она, во-первых, обладает широким кругом компетенций - от инжиниринговой проработки помещений до подготовки проекта очистных сооружений-и, во-вторых, предлагает технологическое сопровождение как продукт, за который несет ответственность. Это ценно: немногие поставщики готовы браться за столь полноформатные программы сотрудничества.

\section{Как вы можете описать характер вашего производства?}

По количеству изделий, выпускаемых для основных заказчиков, мы представляем собой типичное мелкосерийное производство. При этом часто наши платы имеют сложную форму, а разнообразие их конструкций достигает и превышает 500 видов; многослойные ПП на сегодня составляют 15-20\% от общего выпуска, остальное - одно- и двухсторонние.

\section{Какие задачи вы ставите перед собой на ближайшее будущее?}

Производство ПП проектировалось под объемы выпуска, превышающие плановый уровень загрузки по основным типам изделий: было бы непредусмотрительно заранее лишать себя запаса мощностей на случай необходимости увеличения объемов выпуска основной продукции, а также возможности привлечения дополнительных заказов. Поэтому теперь, когда производство запущено, мы ставим задачу обеспечить оборудование полной загрузкой.

Первый этап на этом пути - окончательный перевод нашей базовой номенклатуры на собственные мощности. Дальше будем предлагать свои услуги предприятиям концерна, в который входит АОМЗ. Мы уже наладили контакты с некоторыми из них, сделали для них платы, провели испытания. Сейчас передаем изготовленные платы для испытаний у заказчиков, а после этого представим результаты на научно-техническом совете концерна. Считаю, перспектива у нас хорошая, поскольку больше в составе объединения нет заводов, имеющих запущенное и отлаженное производство сложных ПП. Наконец, на третьем этапе, после того, как первые два будут реализованы и превратятся в нашу повседневность, будем пробовать заместить поставщиков ПП для предприятий Южного федерального округа.

О составе и особенностях нового производственного комплекса изготовления печатных плат нам рассказала "на местности" начальник технологического бюро печатных пиат АОМЗ Валентина Сергеевна Шпикат.

Валентина Сергеевна, какую технику вы используете на механическом участке?

Сейчас у нас два основных станка. Скоростной сверлильный Posalux Ultraspeed 3600-LZ имеет три станции с высокооборотными - до 170 тыс. об/мин - шпинделями, он применяется в первую очередь для работы с серийными платами, когда важна высокая производительность.

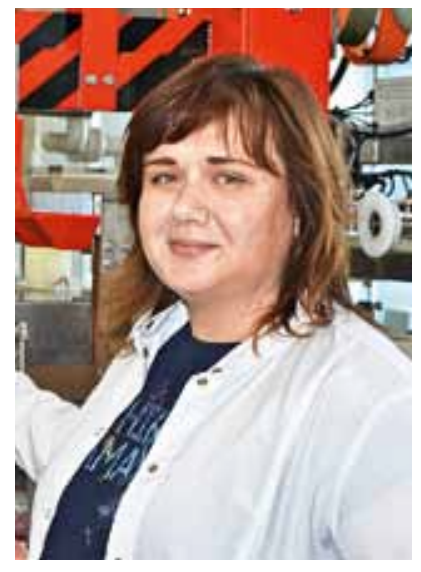

Валентина Шпикат
Перед тем, как подать плату на сверлильный станок, собирается пакет для сверления, в который, кроме самой заготовки (а чаще - нескольких одинаковых заготовок), входят верхняя и нижняя накладки. В пакете сверлятся два отверстия, в которые вставляются скрепляющие штифты. Для одно- и двухсторонних плат эта операция выполняется на установке Matic-DP2. После сверления пакет расштифтовывают, разбирают, и платы переходят на следующие этапы обработки.

Прецизионный сверлильно-фрезерный Posalux Ultraspeed Mono Combi мы выбрали с расчетом на изготовление плат для СВЧ-устройств: на них нужно формировать 


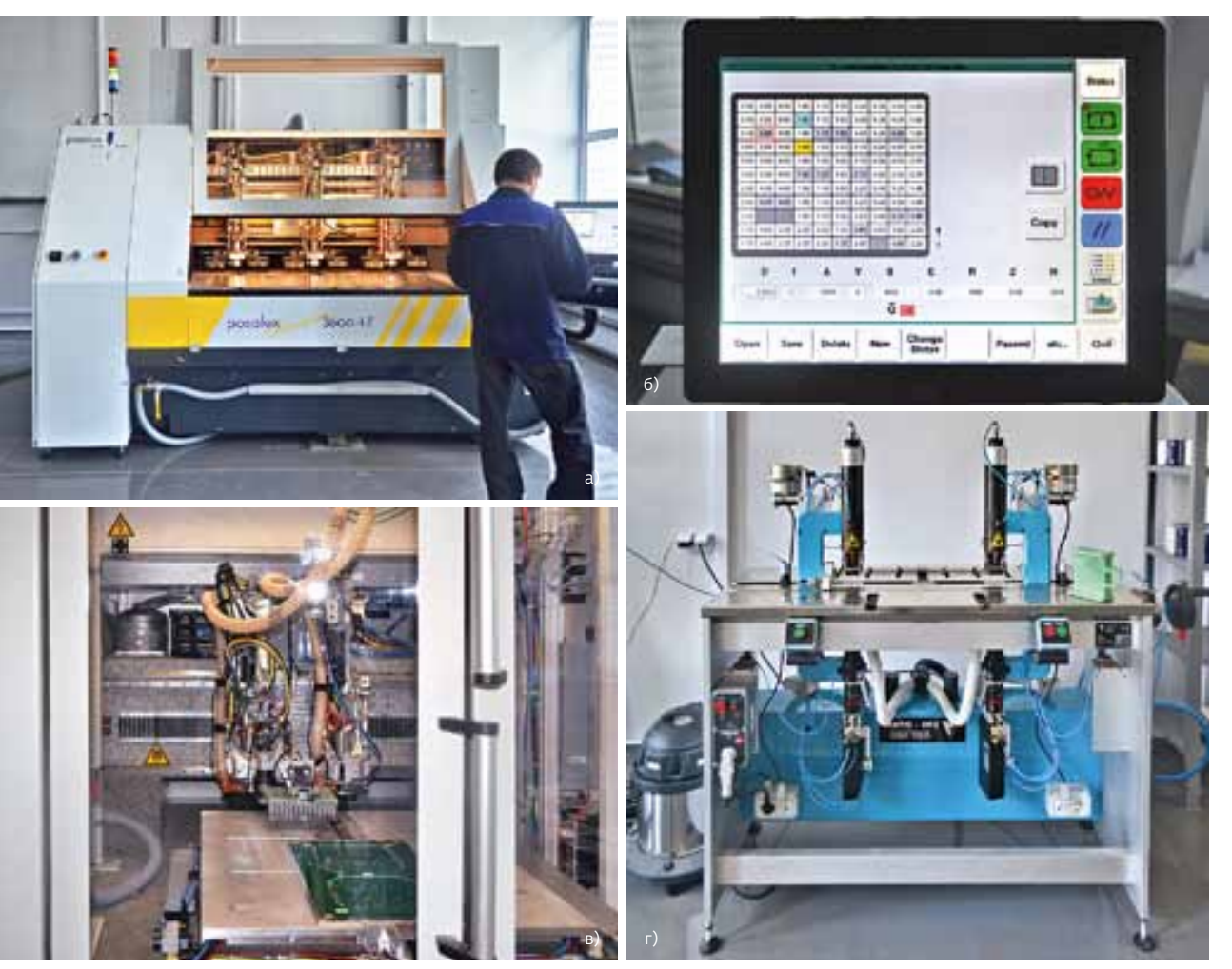

Оборудование механического участка: а - станок Posalux Ultraspeed 3600-LZ; 6 - управляющий экран этого станка с отображением состояния сверл в магазине. Зеленая подсветка - сверло из этой ячейки магазина сейчас находится в шпинделе, серая - сверло уже использовалось, желтая - сверло выработалось, его надо заменить. Красной пунктирной границей отмечена ячейка, которую оператор программирует в данный момент; в - рабочая зона станка Posalux Ultraspeed Mono Combi. Левый шпиндель - фрезерный, правый сверлильный; г - установка сверления двух отверстий и пневматического штифтования пакетов заготовок ПП Matic-DP2 заглубленные металлизированные пазы и контуры с точным соблюдением глубины и формы в плане. Станок имеет одну станцию, но с двумя шпинделями, сверлильным и фрезерным. Число оборотов сверлильного шпинделя до 250 тыс. в мин, фрезерного - до 60 тыс. в мин. Фрезерный шпиндель мощнее, его, кроме фрезерования, используют для сверления отверстий диаметром 4 мм и более. Сверлильный шпиндель применяется в основном для обработки высокоточных плат, он может работать с самыми тонкими сверлами - от 0,05 мм.

Оба станка имеют систему контроля вертикального положения шпинделя над поверхностью, позволяющую сверлить и фрезеровать на заданную глубину с точностью 12,5 мкм.

Сверла используются только в пределах их первоначального ресурса?

у нас допускается переточка сверл диаметром от 0,6 мм, но только для работы с одно- и двухсторонними платами. Для сверления МПП переточенные сверла не применяются.

\section{Куда направляются платы после сверления?}

После сверления заготовки передаются на участок "мокрых» процессов и гальваники. Это наш самый большой участок, здесь установлены следующие линии: подготовки поверхности перед нанесением фоторезиста; подготовки поверхности перед прессованием; проявления фоторезиста и защитных паяльных масок; кислотного и щелочного травления; подготовки поверхности перед горячим лужением (процесс HASL) и финишной отмывки после него. Здесь же расположены две гальванические линии, линия иммерсионного золочения и сама установка HASL.

После сверления плата поступает на автоматическую установку зачистки поверхности с жесткими валами и системой промывки водой под давлением, главное назначение которой - удаление заусенцев, оставшихся после механической обработки. Кроме того, установка может применяться для подготовки поверхности перед нанесением фоторезиста.

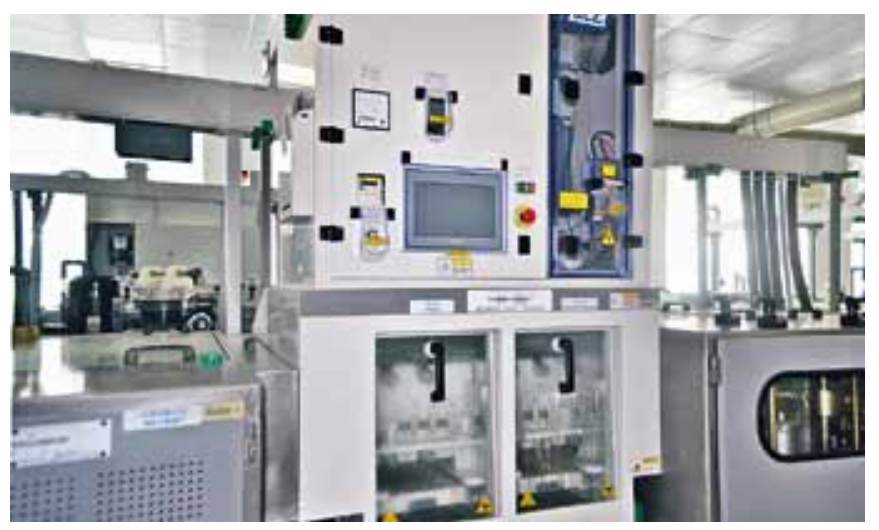

Установка зачистки поверхностей производства компании Universal. Справа - модуль механической обработки, в центре - промывка и шкаф управления (вверху), слева - модуль горячей сушки 


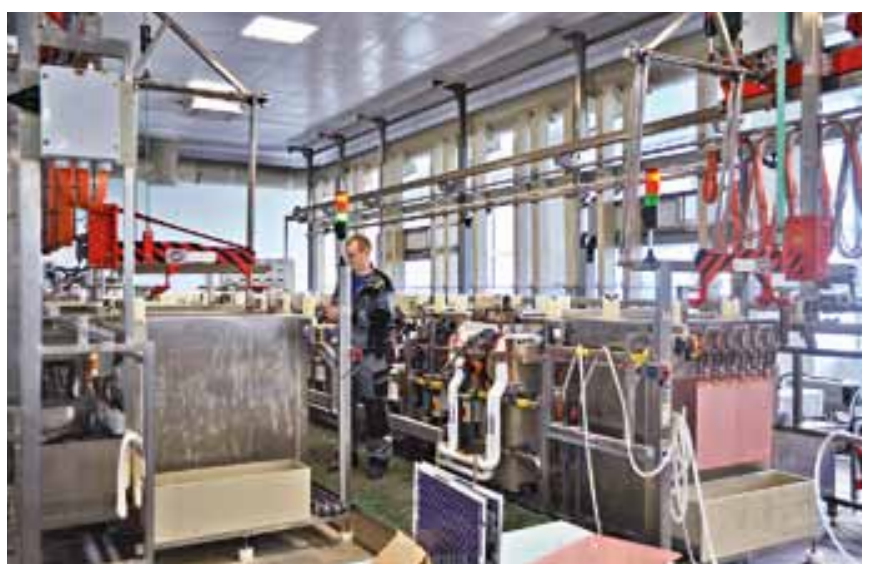

Гальваника: справа - линия химического меднения, слева - гальванического меднения

Теперь можно приступить к металлизации отверстий?

Для этой задачи предназначены две линии компании PAL: одна - для химического меднения, вторая - для гальванического меднения и нанесения металлорезиста.

\section{Почему выбор остановился именно на линиях PAL?}

Эти линии очень хорошо продуманы. В них реализована комбинированная система промывки - погружная и струйная. Струйная система полностью удаляет остатки раствора от предыдущей операции не только из сквозных, но и из глухих отверстий, из всякого рода пазух. Одна лишь погружная система, даже с учетом вибрации подвески, не гарантирует такой результат.

Еще одна особенность линий PAL: в них применена система погружных штанг, на которых в растворе держатся аноды. Обычно они закрепляются на медных штангах, располагающихся над поверхностью раствора, где подвергаются воздействию паров раствора, забрызгиванию, от этого окисляются, возникают проблемы с электрическими контактами. Для того чтобы погруженная в электролит штанга не растворялась сама, как растворяются аноды, ее медный стержень плакирован слоем титана толщиной примерно 1 мм. Результат: штангам в линиях PAL обслуживание требуется примерно на порядок реже, чем штангам обычной конструкции.

Аноды размещаются в титановой корзине. Они представляют собой шарики диаметром порядка 3 см - такая форма обеспечивает равномерное вырабатывание меди и ее распределение в растворе, что также работает на общее качество процесса.

Все, что необходимо, удобно регулируется. В программу вводится площадь обрабатываемой платы, выставляется плотность тока, задается рабочий диапазон температур; если измеренное значение ниже его нижней границы, линия не включится, если ванна перегрелась - автоматически включится охлаждение от чилера.
Конечно, почти все эти функции и конструктивные особенности в том или ином сочетании имеются и у других гальванических линий. Но можно с большой долей уверенности утверждать, что гальванические линии PAL - это лучшее, что можно приобрести в рамках тех цен, которые предлагаются их производителем.

Хотелось бы отметить, что во всех наших химических процессах используются реактивы компании J-КЕМ. Они везде дают хорошие результаты; так, с аддитивными добавками этой компании, применяемыми при металлизации отверстий, мы получаем пластичность меди 20\%, что является очень хорошим результатом для производственной технологии и позволяет без всяких проблем металлизировать отверстия с соотношением диаметра к глубине (aspect ratio, AR) 1:10 и более.

Судя по тому, что мы видим на этом участке, для всех "мокрых" процессов, кроме гальваники, вы используете линии и установки компании Universal.

Кроме гальванических линий PAL, на участке есть и другие исключения, но большинство машин, действительно, произведено китайской фирмой Universal. Оборудование, которое она изготавливает, в последние годы завоевало прочную репутацию в мире, в первую очередь потому, что в своем классе техники машины Universal имеют наилучшиепоказатели по критерию “стоимость-эффективность». Они укомплектованы всеми необходимыми агрегатами и приспособлениями для высококачественного проведения химических процессов, легко конфигурируются под конкретную задачу, надежны, просты в управлении и обслуживании и при этом сто́ят значительно меньше, чем оборудование других производителей со схожими характеристиками.

Возьмем, например, линию щелочного травления. Она оборудована автоматической системой регенерации раствора, поддерживающей концентрацию меди в нем в пределах установленного диапазона. Имеется система автоматического дозирования аммиака, обеспечивающая стабильное значение водородного показателя (pH) раствора. Значение допустимого отклонения является параметром управляющей программы, его можно точно регулировать, что вместе с управлением температурой и плотностью раствора позволяет получить фактор травления 4,5 и более.

Еще одно полезное решение Universal - возможность устанавливать давление для каждой отдельной форсунки, через которые плата омывается травильным раствором; так удается получить высокую однородность стравливания меди по всей поверхности ПП. Причем давление в форсунках устанавливается с пульта, что позволяет оперативно подбирать режим травления, избегая ошибок, возможных при вмешательстве в управляющую программу. 

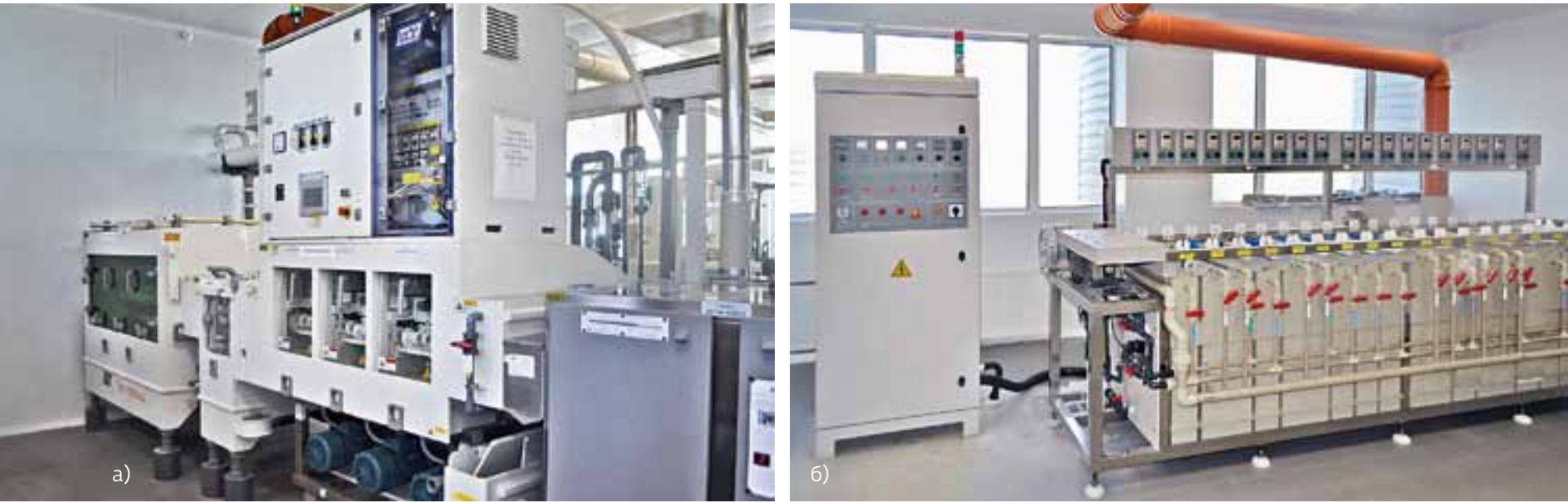

Участок "мокрых" процессов: а - конвейерная установка струйного проявления защитной паяльной маски. Шкаф управления, как обычно у Universal, смонтирован "вторым этажом"; б - линия иммерсионного золочения. Можно видеть индивидуальные пульты для каждой из ванн линии

Вообще, оборудование компании Universal хорошо приспособлено к потребностям многономенклатурного производства. Впрочем, то же самое можно сказать обо всех машинах участка "мокрых» процессов. Например, линия иммерсионного золочения. Сообразуясь с планируемыми объемами выпуска продукции, мы выбрали установку фирмы Baoding Landun с ручной «логистикой»: оператор сам переносит подвески с платами из одной ванны в другую. Но при этом на небольшом индивидуальном пульте каждой ванны выставляется время, необходимое для прохождения процесса, и по его истечении подается сигнал, так что ошибки, связанные с человеческим фактором, сведены к минимуму. Кроме того, технолог получает возможность оперативно регулировать длительность процессов, что значительно облегчает подбор параметров при освоении нового изделия - если бы длительность протекания процессов управлялась компьютером, то при каждом ее изменении приходилось бы переписывать программу, внося корректировки в общий цикл работы установки.

Есть еще какие-то качества, которые добавляют привлекательности оборудованию Universal?

Еще одно достоинство машин Universal - их эргономика. Шкафы управления расположены "вторым ярусом», это не только экономит площадь, но оберегает их от проливов и забрызгивания, вполне возможных в помещении, по которому транспортируется множество различных химических растворов. Оборудование опирается на стойки, и все коммуникации проходят под ним - нет опасности споткнуться о трубу, необходимости перетаскивать через нее тележку при перевозке тяжестей.

краны на коммуникациях окрашены в три разных цвета: синими имеют право манипулировать операторы, зелеными - только инженеры-технологи, доступ к красным - только в особых случаях по специальному распоряжению.

Китайские дизайнеры далеко продвинулись в создании самых незначительных удобств. Например, в подходящем месте машины устроен контейнер, в котором хранятся чистые форсунки для оперативной замены; сделаны карманы для инструмента, а стеклянные крышки отсеков, снятые для доступа к агрегатам и органам управления, не надо ставить на пол - на стенке машины есть гнезда, куда они вставляются специальными пластмассовыми кронштейнами.

\section{Вы сказали про иммерсионное золочение. Какие еще} виды защитных покрытий вы применяете?

Кроме иммерсионного золочения, мы применяем горячее лужение - HASL-процесс - и иммерсионное оловянирование.

Горячее лужение выполняется на трех установках. Первая реализует подготовительные процессы: очистку, микротравление для создания шероховатостей на поверхности меди и флюсование. Затем плату отправляют собственно в установку горячего лужения. Далее плату нужно отмыть, но сразу облить ее водой нельзя, это вызовет недопустимое коробление. Кроме того, существует проблема повреждения мягкой еще поверхности припоя при соприкосновении с элементами конструкции машины. Инженеры Universal нашли эффективное решение: отверстия в нижней поверхности входного конвейера создают под платой воздушную подушку, по которой она, благодаря наклону конвейера, под собственным весом перемещается в его середину, где ее останавливают выдвинувшиеся штифты. Плата остывает до комнатной температуры, штифты убираются, и она “доплывает» до роликового конвейера модуля финишной отмывки. 
Почему нужны три вида финишных покрытий?

Каждому из них присущи свои преимущества и недостатки, определяющие область его оптимального использования.

HASL-покрытие отлично паяется, хорошо сохраняется. Его недостатокнаплывы припоя и разновысотность, что ограничивает применимость этого покрытия для поверхностного монтажа.

Иммерсионное золото дает прекрасную поверхность для монтажа и, кроме того, допускает монтаж разваркой. Наиболее серьезный его недостаток - проблемы экологического характера. Как известно, при осаждении золота используется подслой никеля и раствор на основе уксусной кислоты; соли никеля обладают канцерогенными свойствами, горячая уксусная кислота - весьма агрессивное вещество. Вдобавок смесь компонентов раствора химического никеля трудно утилизируется. Ну и, конечно, золото как драгметалл очень дорого.

Иммерсионное олово образует такое же по качеству покрытие, как иммерсионное золото, только не позволяющее проводить сварку. Прежде этот тип покрытия имел существенный недостаток: оно сохраняло тре-

буемый уровень паяемости в течение двух недель, а потом портилось в результате образования интерметаллического соединения олова и меди. Для преодоления этого

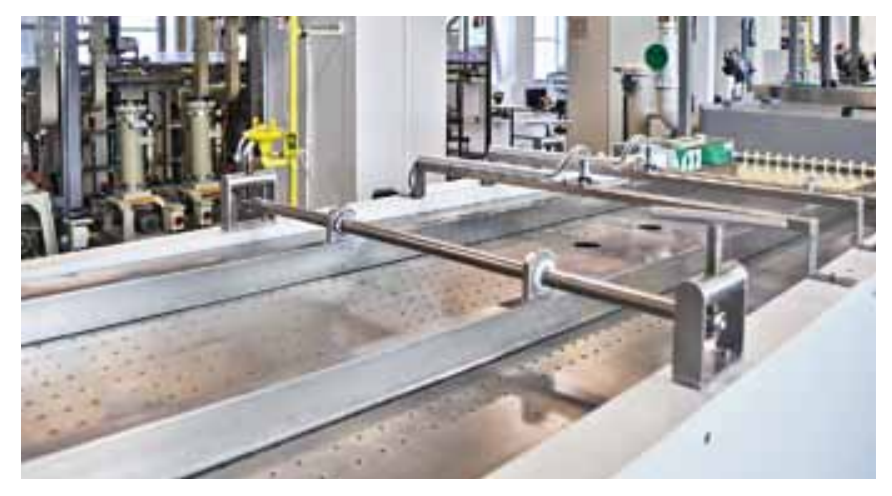

Перфорированный наклонный конвейер линии финишной отмывки, на котором плата остывает после прохождения воздушных ножей установки HASL. Направляющие конвейера регулируются по ширине платы

недостатка была разработана технология с разделением меди и олова подслоем электропроводящей органики; именно этот метод реализуется в нашей установке. Даже с таким усложнением процесс гораздо проще, чем иммерсионное золочение, требует меньше временны́х и энергетических затрат и, конечно, значительно дешевле вследствие низкой стоимости основного материала покрытия.

Мы уже дошли до финишных покрытий, но пропустили ряд предшествующих этапов изготовления плат. Какое оборудование вы используете для работы с фоторезистом?

Для формирования проводящего медного рисунка мы применяем установку прямого экспонирования Apollon D1-A11 швейцарской компании Printprocess. Эта компания создает, вероятно, лучшие в мире системы совмещения, и такая система, интегрированная в Apollon, производит эту операцию с погрешностью, не превышающей 5 мкм. Рабочее разрешение установки - 40 мкм при максимальном 20 мкм, практическая производительность 

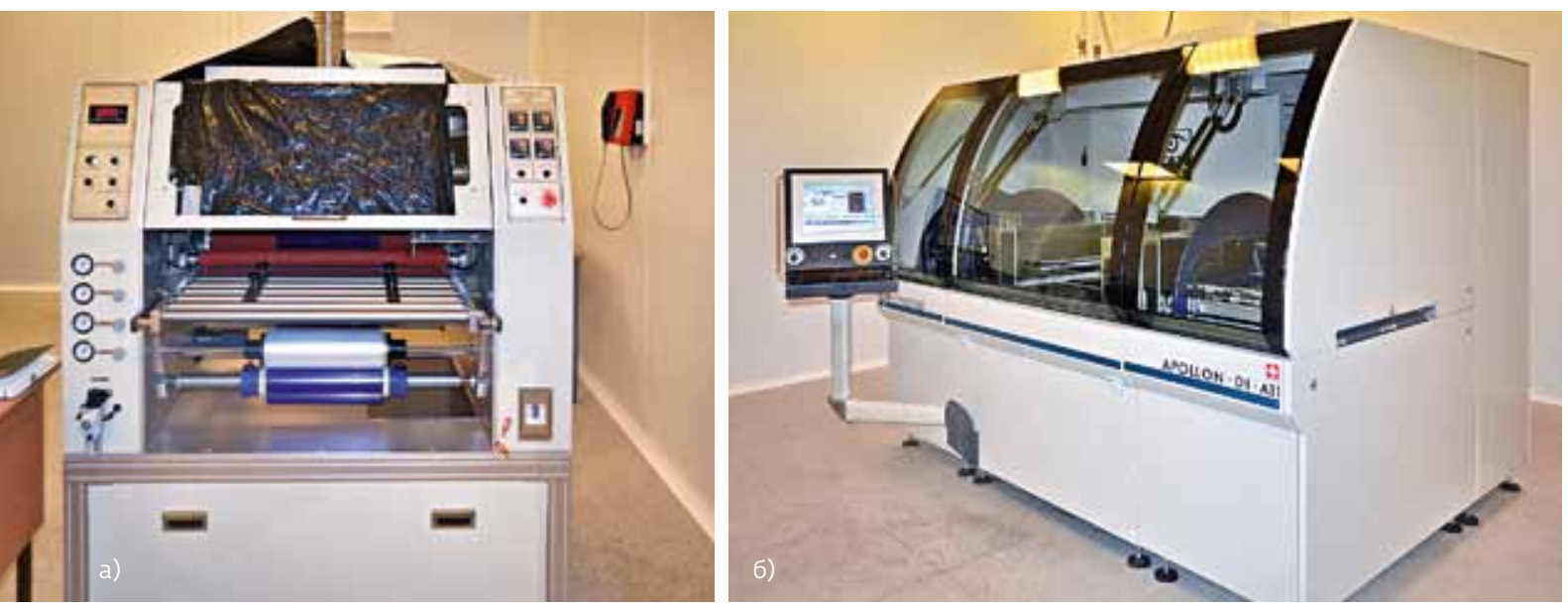

Фотолито-

графия:

а - ламинатор

WAT 100F-LH

корейской ком-

пании ОтS;

б - установка

прямого экс-

понирования

Apollon D1-A11

по фоторезисту - 10 с на сторону заготовки размером $305 \times 457$ мм

Сухой пленочный фоторезист наносится на плату при помощи ламинатора WAT100F-LH, проявление производится на одной из машин Universal на участке «мокрых» процессов.

\section{Как вы формируете на плате защитную паяльную маску?}

Для нанесения на платы паяльной маски и маркировки используется трафаретная печать, реализованная в основном на оборудовании компании Gilco. Мы работаем сжидкими светочувствительными паяльными масками от нескольких производителей, двух цветов - зеленого и белого; последние используются для маркировки и в тех случаях, когда имеет значение эффект светоотражения, в частности, при изготовлении светодиодных светильников.

\section{Осталось ознакомиться со сборкой и прессованием многослойных плат...}

Для подготовки медных поверхностей внутренних слоев МПП к прессованию на участке «мокрых» процессов имеется установка, реализующая сравнительно новую технологию TOP BOND компании J-КЕМ. Этот процесс имеет ряд преимуществ по сравнению с традиционно применяемым для той же цели оксидированием, одним из которых является уменьшение размерной нестабильности слоев вследствие низкой по сравнению с оксидированием температуры протекания реакций - не более $50^{\circ} \mathrm{C}$.

Пакет слоев МПП собирается на установке Rivolino компании Printprocess. Перед сборкой каждый слой нужно привязать кее инструментальной базе - просверлить базовые отверстия с учетом усадки, произошедшей на предыдущих этапах обработки. Для этого служит установка Targomat IV той же швейцарской компании. Targomat сравнивает реальное расстояние между реперными знаками слоя ММП сего чертежным значением, вычисляет уход размеров и располагает центры базовых отверстий со сдвигом на половину этого ухода - таким образом вдвое уменьшается погрешность в любой точке МПП.

Надо сказать, что подобная операция производится и после прессования МПП-перед сверлением в ней сквозных переходных отверстий. В этом случае включается в работу еще одно изделие компании Printprocess - установка вскрытия реперных знаков Targomil. Внешние слои МПП на этом этапе еще полностью покрыты фольгой, и Targomil двумя своими шпинделями, сверху и снизу, производит фрезерование на заданную глубину в местах расположения реперов на внутренних слоях. Теперь можно перемещать заготовку на Targomat, который установит уход размеров после прессования и расположит с его учетом базовые отверстия для сверлильного станка.
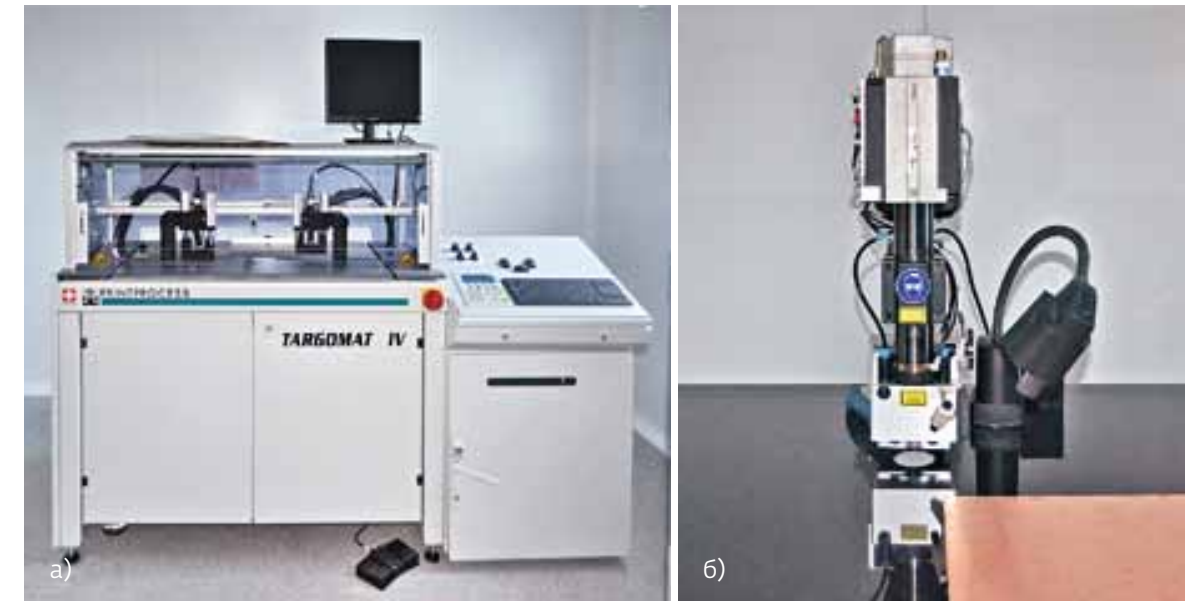

Оборудование для формирования базовых отверстий: a - Targomat IV; 6 - Targomil 

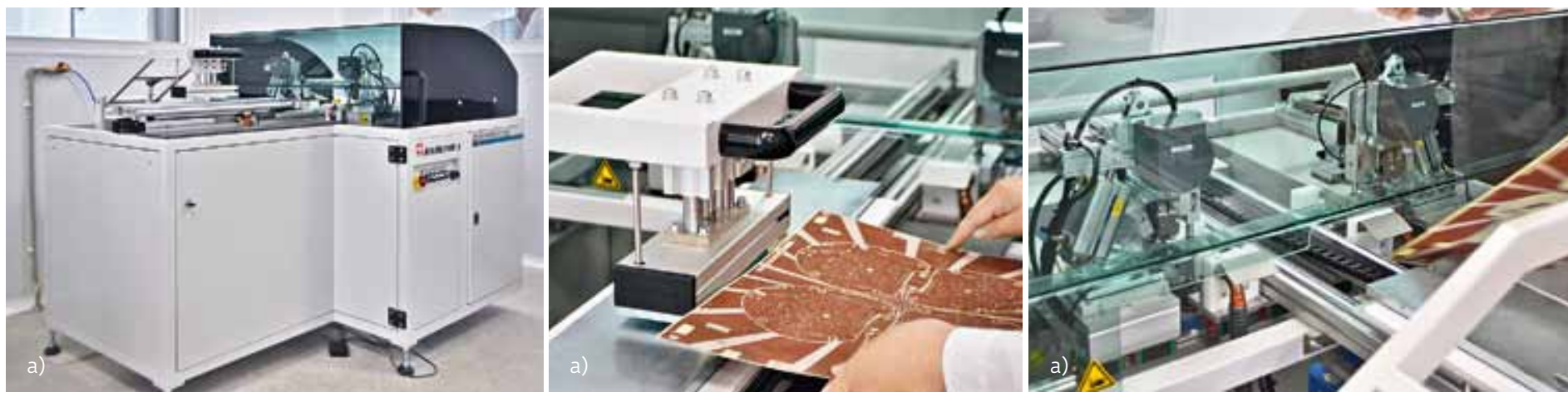

Установка сборки заготовки МПП Rivolino: а - общий вид; б - прижимное приспособление - «утюжок»; в - зона склепки

Давайте вернемся к сборке заготовки МПП.

Метод сборки, реализуемый на установке Rivolino, бесштифтовый, на заклепках. На сборочном столе установки слой за слоем собирается пакет МПП, зажимается специальным приспособлением - мы называем его "утюжком»; затем задается расстояние между заклепками, и пакет отправляется в рабочую зону.

Процесс склепывания состоит из сверления отверстий, вставления в них заклепок и их расклепывания. Всё это происходит автоматически, одновременно с двух сторон пакета.

\section{Теперь можно переходить к прессованию?}

Мы пользуемся двухъярусным вакуумным прессом MP-50-2VK компании HML, у нее же приобретен и весь комплект оборудования для сборки пресс-форм. Заготовки, склепанные на Rivolino, поступают на линию сборки-разборки пресс-форм, в каждую из которых укладывают по три заготовки. Составные части пресс-формы весьма массивны, поэтому линия снабжена магнитным манипулятором.

Для удобства загрузки пресс-формы доставляются к прессу в стокере - раме с направляющими, расположение которых соответствует по высоте ярусам пресса. Для загрузки в стокер пресс-форм, весящих в сборе около 100 кг, служит пневматический лифт, для их перемещения к прессу - транспортная тележка с подъемным механизмом.

Дальше - сверление сквозных отверстий, их химическое меднение, фотолитография, гальваническое осаждение меди, защита металлорезистом, травление внешних слоев, контрольные операции, финишное покрытие, нанесение защитной паяльной маски, маркировка. Плата готова к монтажу.

\section{Какое оборудование вы применяете для контроля вы-} пускаемых плат?

Помимо обычного визуального контроля, мы проверяем качество воспроизведенной на внутренних и внешних
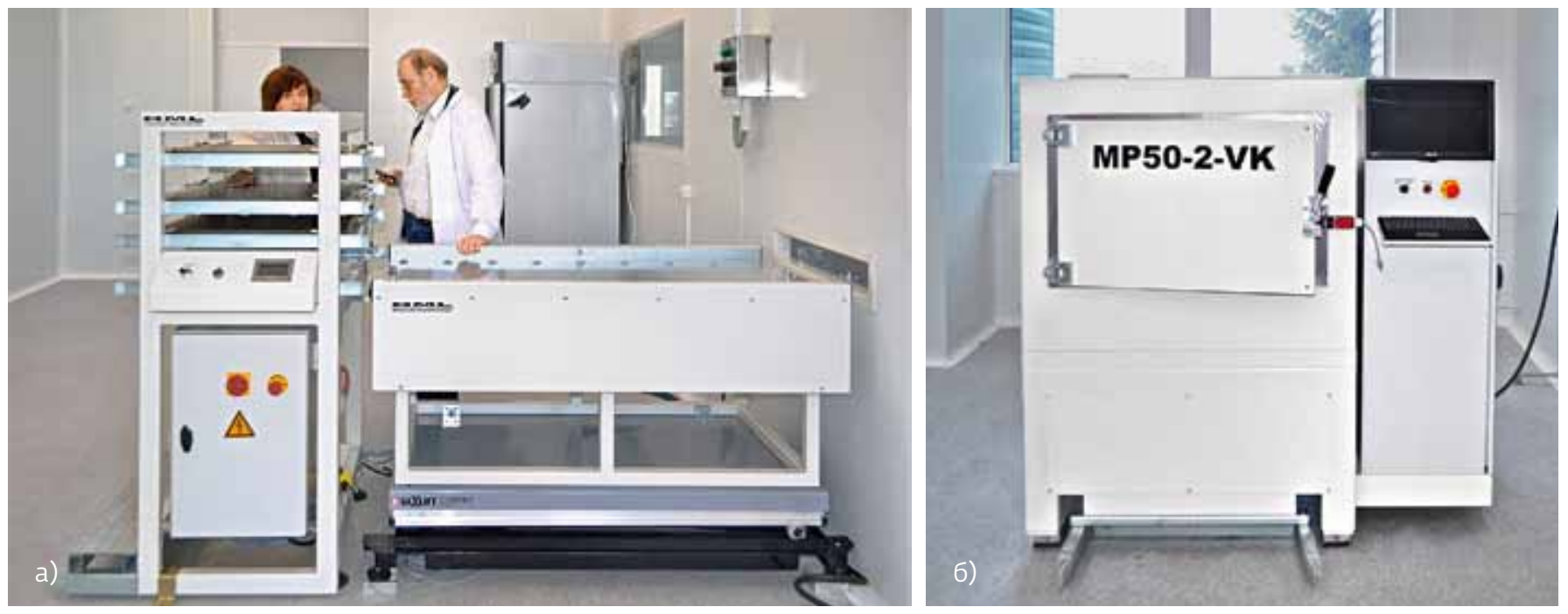

Оборудование, используемое в технологической цепочке подготовки и прессования МПП: а - пневматический лифт. Справа в стене - шлюзовое окно между помещениями разных классов чистоты; 6 - двухъярусный вакуумный пресс HML MP-50-2VK 


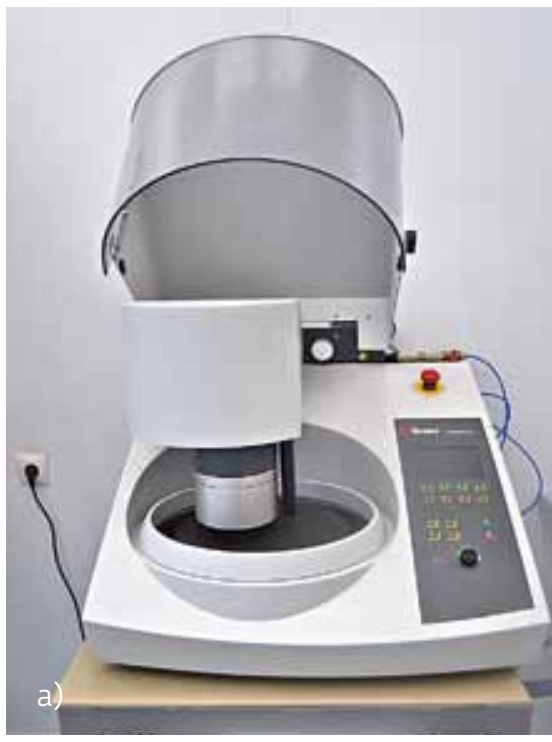

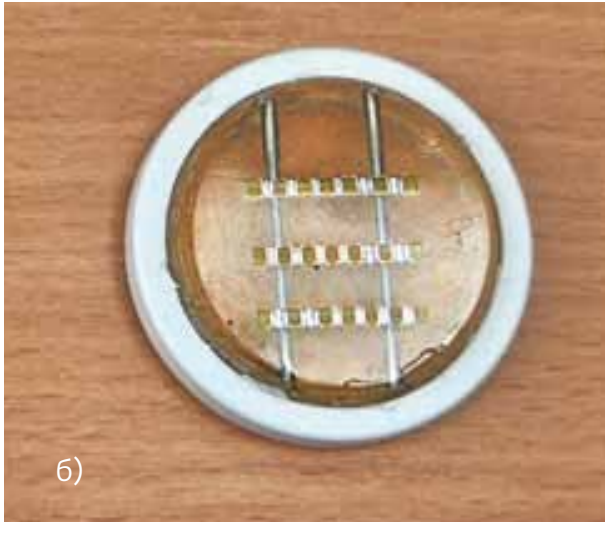

Участок микрошлифов: а - шлифовально-полировальный станок Tegramin-30; б - микрошлиф, готовый к исследованию платы. Не менее важную роль он играет при отработке технологии для новых изделий и материалов. Самый простой пример: на тестовой плате из нового материала просверливаем, скажем, 1000 отверстий и потом вырезаем тест-купоны через каждые 100 отверстий - так устанавливается ресурс сверла данного диаметра на данной толщине данного материала. Или на многослойной плате сверлим отверстия диаметром от 0,2 до 1,8 мм при разном числе оборотов и скорости подачи, исследуем шлифы - на этом материале подбирается оптимальный режим сверления. слоях топологии с помощью автоматической оптической инспекции Orbotec Discovery II 8200. Производится также электрический контроль плат, для чего используется автоматический тестер с "летающими щупами» модели Space Light ESL-610 - машина, способная работать с материалами толщиной от 0,1 мм.

\section{Как вы контролируете качество самого технологиче- ского процесса?}

Наиболее полное представление о состоянии основных технологических процессов дает контроль качества исполнения элементов ПП по микрошлифам. На заготовке каждой платы при проектировании закладываются тесткупоны, число которых зависит от сложности платы. Каждый купон содержит отверстия, просверленные сверлами тех диаметров, которые используются при изготовлении данной ПП. Вместе с платой купоны проходят все стадии технологического процесса, а затем вырезаются, и из них изготавливаются микрошлифы.

Изготовление микрошлифа - непростая задача. Требуется вывести его поверхность в плоскость, в которой лежат оси тестовых отверстий, с погрешностью не более „10\%, иначе искажения при измерении толщины металлизации на стенках отверстия будут слишком велики. Это значит, что при диаметре отверстия 0,2 мм отклонение не может превышать 20 мкм.

Операция шлифовки производится на установке Tegramin-30. Это шлифовально-полировальный станок, так как заключительные этапы обработки шлифов представляют собой серию из нескольких операций полирования с уменьшающимся размером абразивных частиц. Изготовленный шлиф анализируется на микроскопе фирмы Olympus под управлением компьютерной программы.

Надо отметить, что контроль по микрошлифу нужен не только для того, чтобы убедится в годности данной
Вы говорите - исследуем микрошлиф. Какие его элементы оцениваются в таком исследовании?

Мы можем посмотреть форму отверстий и толщину их металлизации, обнаружить ее разрывы, проверить соединение меди на стенках отверстия с медью контактной площадки; можем увидеть наносы смолы, стеклование и еще многое другое.

Если мы видим, например, отклонения стеклотекстолитовой границы отверстия, или нанос смолы, - значит, что-то было не так со сверлом, если речь идет об освоенном изделии, либо неверно установлен режим сверления, если отрабатываем технологию для новой платы. Нанос смолы может также свидетельствовать о недостаточно эффективной очистке в ходе процесса химического меднения. Вообще же информация, которую дает анализ микрошлифов, позволяет сделать выводы практически по всем операциям технологического процесса.

Вы уже провели обширный цикл подобных исследований на новом оборудовании. Расскажите о каком-нибудь из таких испытаний.

В одной из опытных работ проверялось качество металлизации отверстий с большим соотношением глубины к диаметру. Проверка проводилась на высоконасыщенных многослойных ПП из двух разных базовых материалов, одна из них имела толщину 2,0 мм, другая - 2,1 мм. Отверстия имели диаметр 0,2 мм. Контроль по микрошлифам показал, что все отверстия получили сплошную, без изъянов металлизацию одинаковой по всей поверхности толщины 35 мкм при допуске $\pm 10 \%$. То есть мы можем гарантировать безупречное качество металлизации отверстий с $A R=10$, а, скорее всего, и больше.

\section{Спасибо за интересный рассказ.}




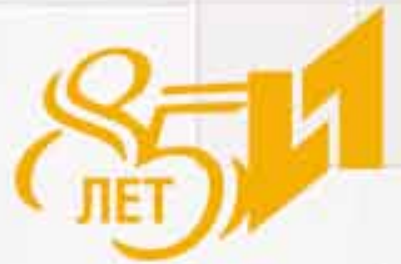

ИРКУТСКИЙ РЕЛЕЙНЫЙ

ЗАВОД

АКUИОНЕРКОЕ ОБЩЕСTHO

Россия, 664075, Иркутская обл., г. Иркутск, Тел.

ул. Байкапьская, 239

E-mail: marketing@irzirk.ru

www.irzirk.ru

приемная - (3952) 22-60-30

сбыт - тіф (3952) 24-76-19/ 24-57-45;

маркетинг - т/申 (3952) 35-23-18/ 24-56-46;

\section{AО «ИР 3 » предлагает к поставке изделия коммутационной техники}

\section{Реле электромагнитные}

Реле РЭКвз, РЭКвз В - неполяризованные, одностабипьные, герметичные постоянного тока, с двумя переключающими контактами
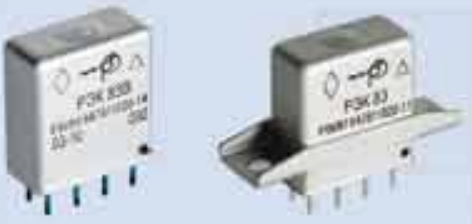

- Коммутируемый ток

до 3 А при индуктивной

нагрузке $\mathrm{C} \tau \leq 5 \mathrm{MC}$;

0.1 - 5.0 А постоянного тока:

$0.1-0.5$ A переменного тока.

- Коммутируемое напряжение

12 - 34 постоянного тока:

12 - 115 Взфф переменного тока.

- Гарантийный срок службы 25 лет.

Монтаж реле в аппаратуру

осуществляется пайкой на печатную

плату или за рамку еинтами.

Penе PЭС48, РЭС48 В - неполяризованные, одностабипьные, герметичные, постоянного тока, с двумя перекпючающими контактами.

Penе PЭС 48-1, РЭС48-1 В - с ппанарными выводами Аля поверхностного монтака на печатной плате (модификация реле РЭС48, РЭС48 В).

- Коммутируемый ток.

$10^{-6}$ - 3,0 A постоянного тока:

$0,1-1,5$ A переменного тока.

- Коммутируемсе напряжение.

$0,05-220$ B nостоянного тока:

12 - 150 Взфф переменного тока.

- Гарантийный срок спужбы 12 или 25 лет.

Тип монтажа реле; навесной, печапный, поеерхностный
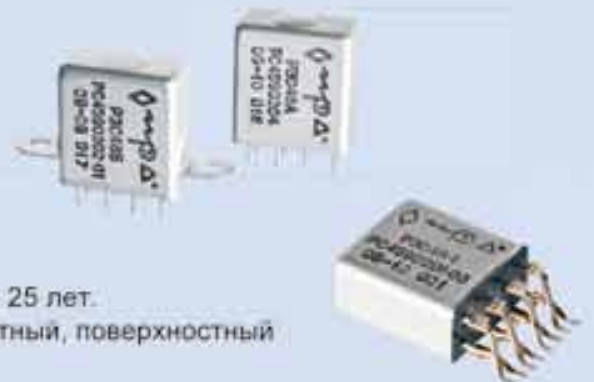

Радиочастотные соединители

Соединители радиочастотные врубные, герметичные и негерметичные КАПД. 434511.019 ТУ. Рабочий диапазон частот до 40 ГТч, присоединительные размеры типа SMP по стандарту MIL-STD-348B, Fig. 326.

\begin{tabular}{|c|c|c|}
\hline $\begin{array}{l}\text { Наименование } \\
\text { соединителя }\end{array}$ & Тип кабеля & $\begin{array}{c}\text { Внешний } \\
\text { вид }\end{array}$ \\
\hline \multicolumn{3}{|c|}{ Розетка кабельная прямая } \\
\hline CP- $50-969 \Phi B-00$ & $0,047^{*}$ & \\
\hline СР-50-969ФB-01 & $\begin{array}{l}\text { PK50-1-23, } \\
\text { PK50-1-24 }\end{array}$ & \\
\hline CP-50-969ФB-02 & $\begin{array}{c}0,086^{\prime \prime} \\
\text { PK50-1,5-22 }\end{array}$ & \\
\hline
\end{tabular}

Розетка кабельная угповая

\begin{tabular}{lc}
\hline CP-50-970ФB-00 & 0,047 \\
\hline CP-50-970ФB-01 & $\begin{array}{l}\text { PK50-1-23, } \\
\text { PK50-1-24 } \\
\text { CP-50-970ФB-02 }\end{array}$ \\
\hline $\begin{array}{c}0,086 \\
\text { PK50-1,5-22 }\end{array}$
\end{tabular}

Розетка кабельная прямая

\begin{tabular}{lc}
\hline CP-50-971ФB-00 & $0,047^{\circ}$ \\
\hline CP-50-971ФB-01 & $\begin{array}{l}\text { PK50-1-23, } \\
\text { PK50-1-24 }\end{array}$ \\
\hline CP-50-971ФB-02 & $\begin{array}{l}0,086^{\circ}, \\
\text { PK50-1,5-22 }\end{array}$ \\
\hline
\end{tabular}

Переход герметичный микрополосковый CPr-50-972B

\section{Bunka}

Anя nоверхностного монтажа CP-50-973B

Переход розетка-розетка CP- $50-968 \oplus B$

Переход герметичный вилка-виліка CPT.50-974B

Соединители радиочастотные с присоединительными размерами типа IX и SMA в соответствии с ГОСТ РB 51914-2002. Рабочий диапазон частот до $18 \mathrm{rTu}$

Вилки кабельные СР-50 ОКР кПереход-2w по разработке и освоению в производстве прямой и угловой кабельных вилок СР-50 Разработаны исполнения под спедующие типы кабеепя: PK-50-1, 5-22: PK-50-2-25: PK-50-3-28; PK-50-3-29; SR-085 RG-405; $0.086^{\prime \prime}, 0.113^{\prime \prime}, 0.141^{\prime \prime}$

\section{Соединители радиочастотные} герметичные СРГ-50 (КМПП) Подтверждена работоспособ̆ность издепий при пониженном атмосферном давлении $1,33 \cdot 10+7 \mathrm{Ta}$ $\left(1 \cdot 10^{-6}\right.$ мм рт. ст.) в установившемся режиме. Соответствуоцие изменения внесены в технические усповия ФИМД 430421.001 ТУ
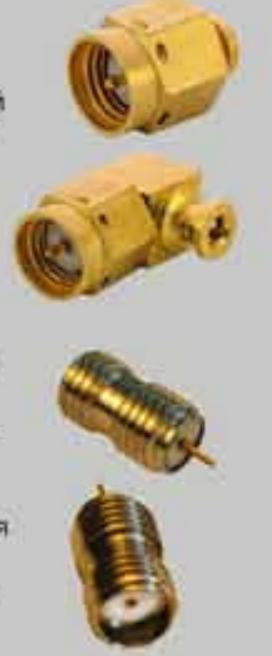

пыпеводонепроницаемьй перекnичатепь с безобрывным перекпючением контактов имеeт.

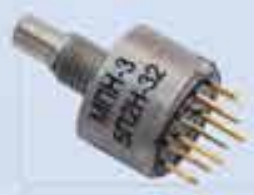
12 эл схем коммутации
- 3 runa sana yправпения
-4 варианта размера вылета
Пылеводонепроницаемый

Категория хачества - «ОТК» и шВПю 